\title{
Rapid Method for the Determination of 5-Hydroxymethylfurfural and Levulinic Acid Using a Double-Wavelength UV Spectroscopy
}

\author{
Junhua Zhang, ${ }^{1,2}$ Junke Li, ${ }^{1}$ Yanjun Tang, ${ }^{1}$ and Guoxin Xue ${ }^{1}$ \\ ${ }^{1}$ Engineering Research Center for Eco-Dyeing and Finishing of Textiles, Ministry of Education, Zhejiang Sci-Tech University, \\ Hangzhou 310018, China \\ ${ }^{2}$ Key Lab. of Biomass Energy and Material, Nanjing 210000, China
}

Correspondence should be addressed to Junhua Zhang; zhangjh@zstu.edu.cn

Received 4 August 2013; Accepted 27 August 2013

Academic Editors: H. Filik and I. Garrard

Copyright (C) 2013 Junhua Zhang et al. This is an open access article distributed under the Creative Commons Attribution License, which permits unrestricted use, distribution, and reproduction in any medium, provided the original work is properly cited.

\begin{abstract}
This study reports on a rapid method for the determination of levulinic acid (LA) and 5-hydroxymethylfurfural (HMF) in acid hydrolyze system of glucose based on UV spectroscopy. It was found that HMF and LA have a maximum absorption at the wavelengths of $284 \mathrm{~nm}$ and $266 \mathrm{~nm}$, respectively, in a water medium, and the absorptions of HMF and LA at $284 \mathrm{~nm}$ and $266 \mathrm{~nm}$ follow Beer's law very well. However, it was found that a major spectral interference species will arise in the quantification of HMF and LA; nonetheless, this interference can be eliminated through the absorption treatment of charcoal. Therefore, both HMF and LA can be quantified with a double-wavelength technique. The repeatability of the method had a relative standard deviation of less than $4.47 \%$ for HMF and $2.25 \%$ for LA; the limit of quantification (LOQ) was $0.017 \mathrm{mmol} / \mathrm{L}$ for $\mathrm{HMF}$ and $4.68 \mathrm{mmol} / \mathrm{L}$ for LA, and the recovery ranged from $88 \%$ to $116 \%$ for HMF and from $94 \%$ to $105 \%$ for LA. The present method is simple, rapid, and accurate. It is suitable to use in the research of the preparation of HMF and LA in biorefinery area.
\end{abstract}

\section{Introduction}

Levulinic acid (LA) can be used as a new platform chemical for the production of a wide range of value-added products through salification, esterification, hydrogenation, condensation, oxidation and halogenation reaction $[1,2]$. So, it will have important stratagem significance for the preparation of LA from biomass resources, especially from non-foodstuff resources [3]. The preparation of LA often requires the use of stalk or the solid abandon matter which contains cellulose as the origination material and was first hydrolyzed to glucose or fructose at high temperature, and the formed sugar was dehydrated to LA via a platform chemical of $\operatorname{HMF}[4,5]$. Therefore, understanding the production law of HMF and LA in the acid hydrolyzed system of glucose or fructose will have an important significance, and the concentration measurement of HMF and LA in the acid hydrolyzed system will be the emphasis premise.

The traditional quantitative analysis for HMF included thiobarbi acid method [6] and thiosemicarbazone method [7]. However, thiobarbi acid method should remove the deposit that was generated during the Winkler reaction; thiosemicarbazone method in the sample should be distilled, and both methods need chromogenic reaction before analysis [8]. In recent years, ion chromatography (IC), high performance liquid chromatography (HPLC) [9-12], and gas chromatography (GC) [13-16] also have been used for the analysis of HMF and LA; however, these instruments are expensive and the relative maintenance costs are high.

In this work, we have developed a UV spectroscopic method for the simultaneous determination of HMF and LA. 
The present method is simple, rapid, and accurate and has the potential for online process monitoring.

\section{Experimental Section}

2.1. Chemicals. All chemicals used in the experiments were from commercial sources. Five HMF solutions (the concentration range is from 0 to $0.1 \mathrm{mmol} / \mathrm{L}$ ) and $\mathrm{LA}$ solutions (the concentration range is from 0 to $65 \mathrm{mmol} / \mathrm{L}$ ), analytical grade, were used as the standard for calibration. A $5 \mathrm{wt} \%$ of $\mathrm{H}_{2} \mathrm{SO}_{4}$ solution was used to hydrolyze glucose.

2.2. Samples. Seven stream samples were collected from the $\mathrm{H}_{2} \mathrm{SO}_{4}$ solution hydrolyze system of glucose in the laboratory using a reaction kettle. The process conditions of acid hydrolyze system experiments were as follows: $3 \mathrm{~g}$ of glucose was used, $50 \mathrm{~mL}$ of $\mathrm{H}_{2} \mathrm{SO}_{4}$ solution ( $5 \mathrm{wt} \%$ ) was poured into the reaction kettle, the reactor was placed in the electricity bath and heated to $180^{\circ} \mathrm{C}$, and time was recorded from the set-value temperature. The reaction was stopped after $2 \mathrm{~h}$ from the start of the reaction and cooled to room temperature.

2.3. Apparatus. A UV-Vis spectrophotometer (S-3100, Shinco, Korea) equipped with a $1 \mathrm{~cm}$ path length flow cell was used for the experiments.

2.4. Procedures. Calibration was conducted by preparing a set of standard solutions, that is, 0.019, 0.037, 0.056, 0.075, and $0.093 \mathrm{mmol} / \mathrm{L}$ of HMF and 20.25, 29.80, 39.00, 47.86, and $64.66 \mathrm{mmol} / \mathrm{L}$ of LA. The absorption spectrum for each solution was measured at wavelength of $284 \mathrm{~nm}$ and $266 \mathrm{~nm}$, respectively.

For a typical UV analysis of glucose hydrolysate, $5 \mathrm{~mL}$ of filtrate for glucose hydrolysate and $0.5 \mathrm{~g}$ of activated charcoal were added to a $10 \mathrm{~mL}$ of colorimetric tube. The solution was boiled for $1 \mathrm{~min}$; then, the reaction solution was filtrated by filter paper, and the filtrate was measured at the wavelength of $284 \mathrm{~nm}$ and $266 \mathrm{~nm}$ after filtration.

\section{Results and Discussion}

3.1. Spectral Characteristics of HMF and LA Complex. UV light can be absorbed by HMF and LA. Therefore, HMF and LA can be determined by spectroscopy as long as there is no spectral interference. As shown in Figure 1, HMF and LA have strong absorption in the UV range below $330 \mathrm{~nm}$, and their characteristic absorption is at wavelength of $284 \mathrm{~nm}$ and $266 \mathrm{~nm}$, respectively. Thus, the concentration of HMF and LA can be measured.

As shown in Figure 2, the absorptions of HMF and LA at $266 \mathrm{~nm}$ and $284 \mathrm{~nm}$ follow Beer's law very well. The molar absorptivity at the wavelength of $266 \mathrm{~nm}$ and $284 \mathrm{~nm}$ is $12.38,22.7 \mathrm{mmol}^{-1} \cdot \mathrm{L} \cdot \mathrm{cm}^{-1}$ for $\mathrm{HMF}$ and 0.023 ,

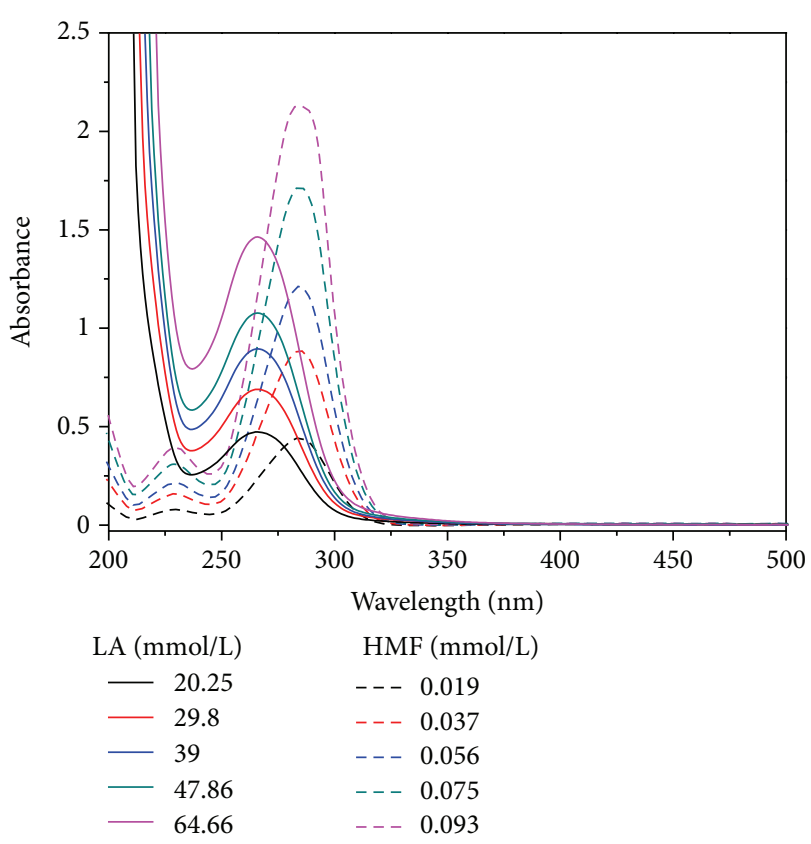

Figure 1: Spectra of HMF and LA.

$0.014 \mathrm{mmol}^{-1} \cdot \mathrm{L} \cdot \mathrm{cm}^{-1}$ for LA, respectively. And the standard calibration curve was obtained; that is,

$$
\begin{gathered}
A_{\mathrm{HMF}, 266}=-0.0055( \pm 0.021)+12.38( \pm 0.37) C \\
\left(n=6, r^{2}=0.9954\right), \\
A_{\mathrm{HMF}, 284}=0.006( \pm 0.029)+22.7( \pm 0.5) C \\
\left(n=6, r^{2}=0.9975\right), \\
A_{\mathrm{LA}, 266}=0.0096( \pm 0.0077)+0.023( \pm 0.0002) C \\
\quad\left(n=6, r^{2}=0.9996\right), \\
A_{\mathrm{LA}, 284}=0.0075( \pm 0.0058)+0.014( \pm 0.0001) C \\
\left(n=6, r^{2}=0.9995\right),
\end{gathered}
$$

where $A_{\mathrm{HMF}, 266}, A_{\mathrm{HMF}, 284}, A_{\mathrm{LA}, 266}, A_{\mathrm{LA}, 284}$, and $C$ represent, respectively, the UV signal response for HMF and LA at $266 \mathrm{~nm}$ and $284 \mathrm{~nm}$ and the HMF and LA concentration (in $\mathrm{mmol} / \mathrm{L}$ ) of the standard samples for HMF and LA. It can be seen from (1) to (4) that there is a good linear relationship at the linear range of $0-0.093 \mathrm{mmol} / \mathrm{L}$ for $\mathrm{HMF}$ and $0-$ $64.66 \mathrm{mmol} / \mathrm{L}$ for LA.

Being calculated by $(5)[17,18]$, the limit of quantitation (LOQ) in the present method is $0.017 \mathrm{mmol} / \mathrm{L}$ for HMF (at $266 \mathrm{~nm}$ ) and $4.68 \mathrm{mmol} / \mathrm{L}$ for LA (at $284 \mathrm{~nm}$ ), which can meet the requirements for glucose hydrolysate test:

$$
\mathrm{LOQ}=\frac{a+10 \times|\Delta a|}{s},
$$

where $a, \Delta a$, and $s$ respresent the intercept, uncertainty of the intercept, and the slope in (1) to (4), respectively. 


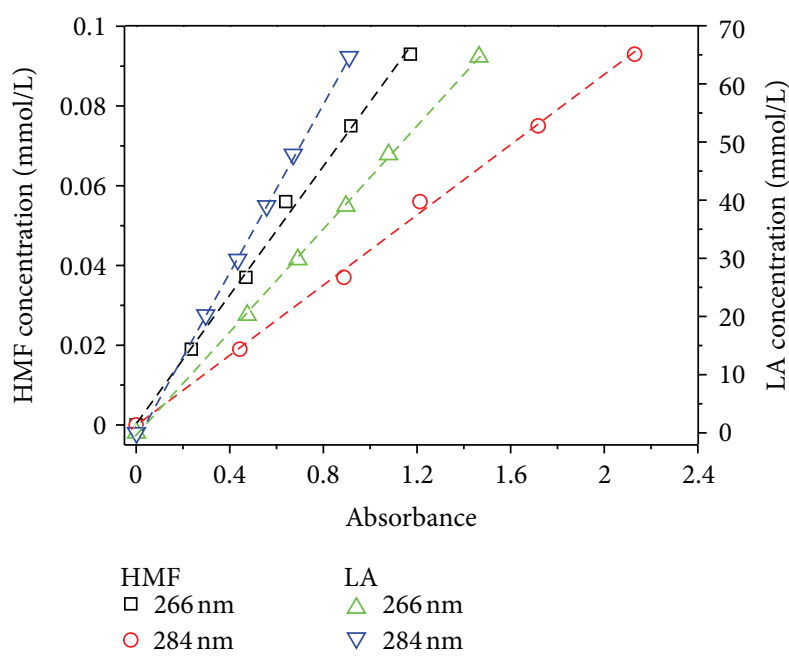

FIGURE 2: Calibration curves for HMF and LA.

3.2. Spectral Interference. For HMF and LA determination in hot acid hydrolysis solution of glucose or fructose, the major spectral interference species are produced by byproducts which are generated by subsidiary reactions during the hot acid hydrolysis. As shown in Figure 3, the standard samples of HMF and LA only have absorption in the UV range below $350 \mathrm{~nm}$; however, the hot acid hydrolysis solution has an obvious absorption in the UV range at wavelengths between $350 \mathrm{~nm}$ and $450 \mathrm{~nm}$. Therefore, the byproducts of the hot acid hydrolysis solution interfere in the determination of HMF and LA by UV spectrophotometry. Fortunately, the charcoal can be used to eliminate the interference. Therefore, the interference of byproducts in HMF and LA determination using the spectral characteristics at wavelengths of $266 \mathrm{~nm}$ and $284 \mathrm{~nm}$ can be neglected.

\subsection{The Elimination of Spectral Interferences}

3.3.1. The Effect Determine of the Charcoal Absorption. The spectral difference of a sample before and after it was treated by charcoal was shown in Figure 4; it can be seen that the absorption in the UV range at wavelengths between $350 \mathrm{~nm}$ and $450 \mathrm{~nm}$ had been eliminated after the adsorption treatment by charcoal. Therefore, the interference of byproducts can be eliminated, and the absorbance of HMF and LA can be determined.

3.3.2. The Dosage of Charcoal Required for the Absorption. The dosage of charcoal can affect the adsorption ratio of byproducts. So, it will influence the spectra of the sample after adsorption treatment by charcoal. As shown in Figure 5, the absorbance of an acid hydrolysis sample at wavelengths between $200 \mathrm{~nm}$ and $600 \mathrm{~nm}$ gradually dropped along with the enhancement of charcoal dosage.

The absorption intensity at wavelengths of $400 \mathrm{~nm}$ as a function of charcoal dosage, which indicated that complete interference was eliminated when the dosage of charcoal achieved $0.1 \mathrm{~g} / \mathrm{mL}$ sample (Figure 6). If a further reduction

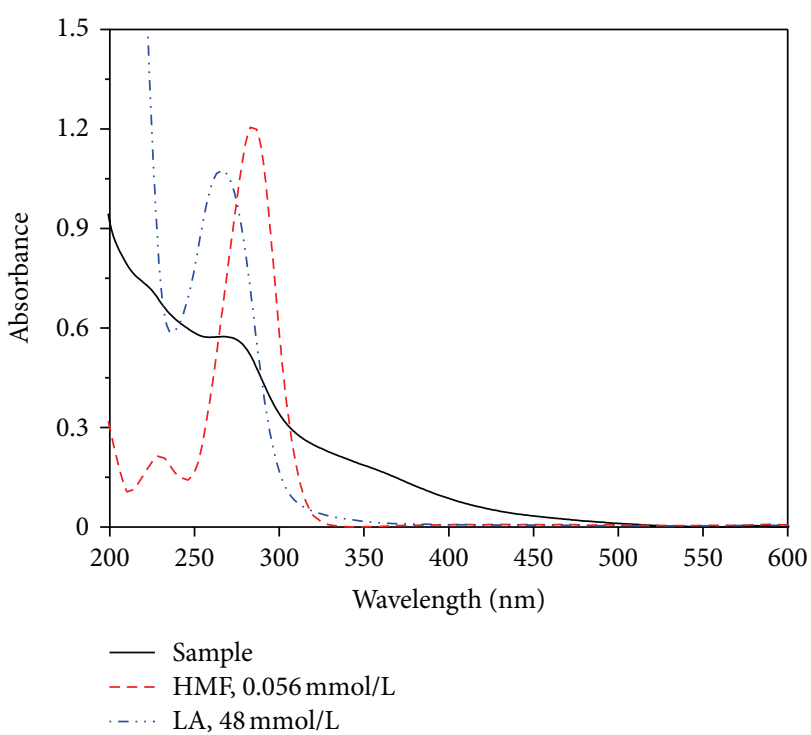

FIGURE 3: Spectra of HMF, LA, and sample.

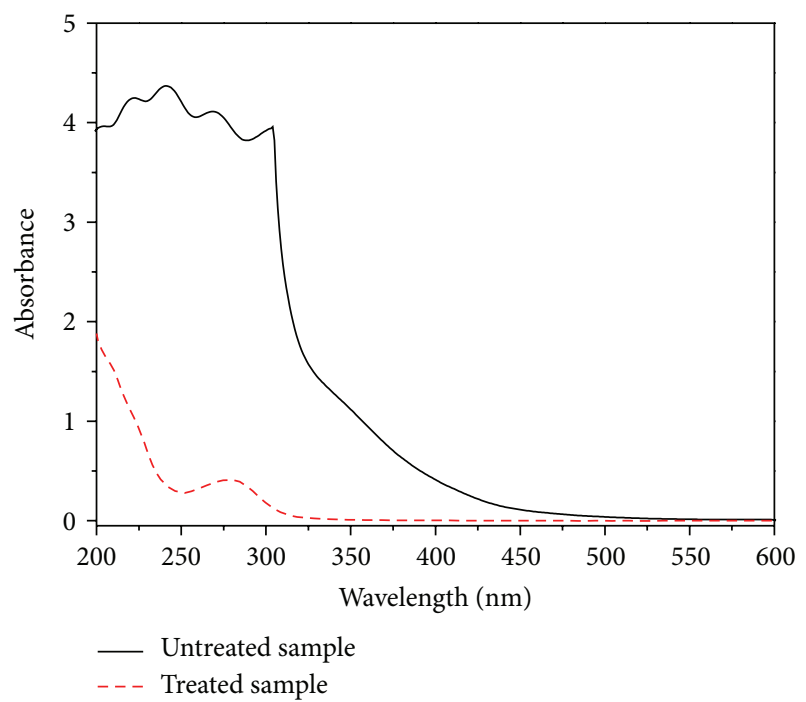

FIGURE 4: Spectra of the sample before and after it was treated by charcoal.

in charcoal dosage is desired, increasing the boiling time can be an option since the adsorption ratio should increase in a long time. However, to avoid further hydrolysis of LA and HMF and to find the proper charcoal dosage at higher temperature, a curve similar to that in Figure 6 should be established. Overall, the present procedure is simpler and faster. It involves a single reaction step and requires less chemicals and analytical equipment.

3.3.3. The Calibration Coefficient Determine of HMF and LA. During the charcoal absorption treatment of the hot acid hydrolysis solution, not only the byproducts were absorbed, but also HMF and LA would be absorbed at a certain extent. Figure 7 shows the spectrograms of HMF and LA 


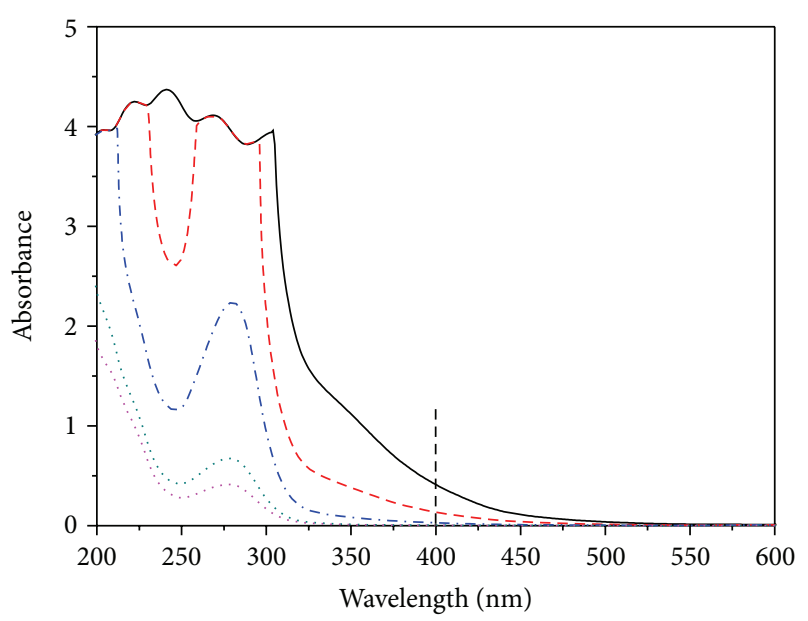

Dosage (g)

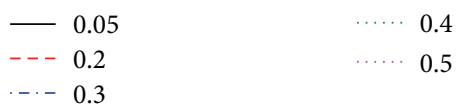

FIGURE 5: Effect of charcoal dosage on the spectra of a sample.

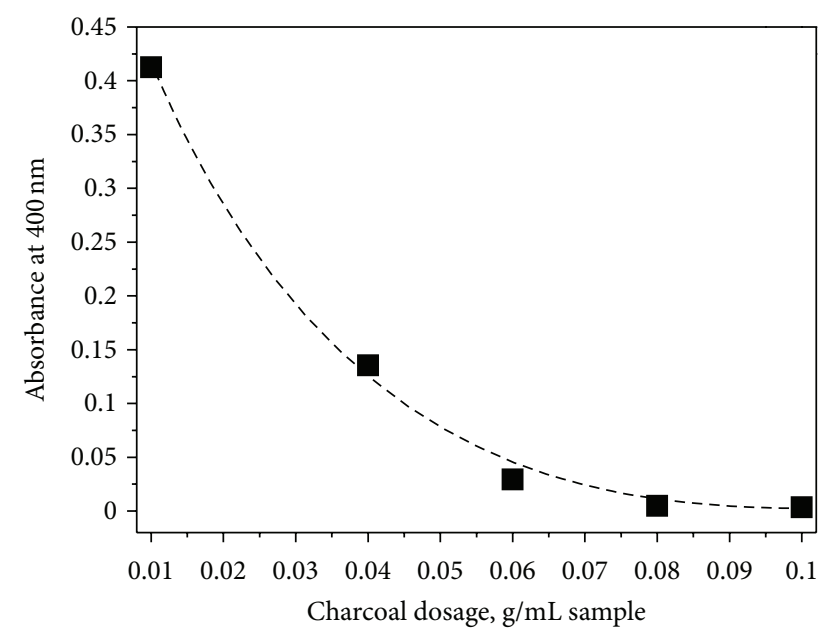

FIGURE 6: Effect of charcoal dosage on the absorbance at $400 \mathrm{~nm}$ of a sample.

standard solutions before and after they were treated by charcoal. So, the calibration coefficients of HMF and LA can be determined, which can be derived as

$$
\begin{gathered}
K_{\mathrm{HMF}}=\frac{A_{b, 284}}{A_{a, 284}}, \\
K_{\mathrm{LA}}=\frac{A_{b, 266}}{A_{a, 266}},
\end{gathered}
$$

where $K_{\mathrm{HMF}}, K_{\mathrm{LA}}$ are the calibration coefficients of $\mathrm{HMF}$ and LA at wavelengths of $284 \mathrm{~nm}$ and $266 \mathrm{~nm}$, respectively. $A_{b, 284}$ and $A_{a, 284}$ are the absorbance of HMF at $284 \mathrm{~nm}$ before and after the standard solution was treated by charcoal. $A_{b, 266}$ and $A_{a, 266}$ are the absorbance of LA at wavelengths of $266 \mathrm{~nm}$ before and after it was treated by charcoal. The calibration

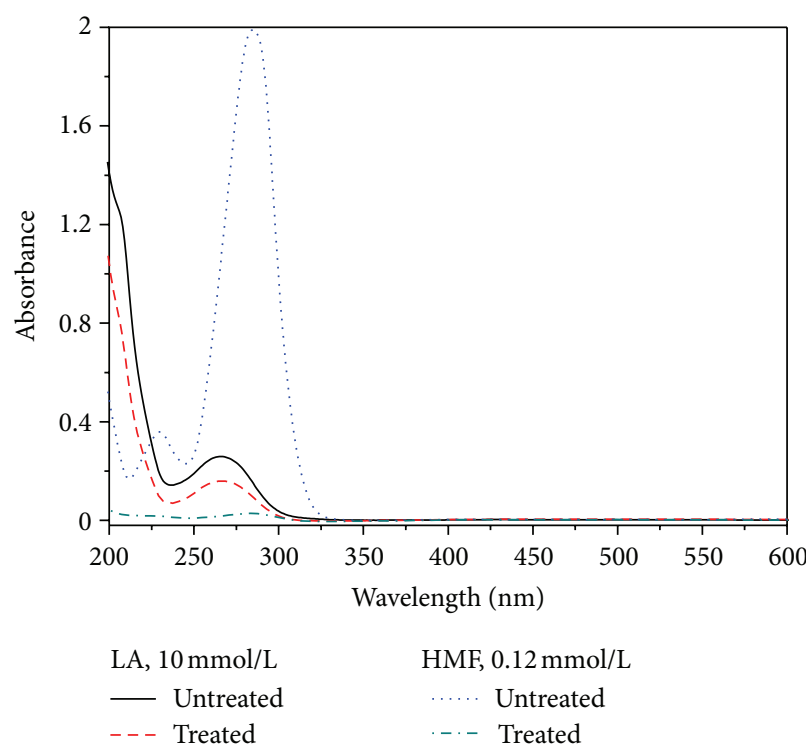

FIGURE 7: Effect of charcoal absorption on the absorbance of LA and HMF.

TABLE 1: Recovery test of the method.

\begin{tabular}{lcccccc}
\hline \multirow{2}{*}{ Sample } & \multicolumn{3}{c}{ Weight, $\mu \mathrm{mol}$} & \multicolumn{2}{c}{} \\
& \multicolumn{2}{c}{ Added } & \multicolumn{2}{c}{ Measured } & \multicolumn{2}{c}{ Recovery, \% } \\
& LA & HMF & LA & HMF & LA & HMF \\
\hline 1 & 34 & 148 & 32 & 130 & 94 & 88 \\
2 & 50 & 123 & 49 & 144 & 98 & 116 \\
3 & 78 & 165 & 84 & 173 & 108 & 104 \\
4 & 97 & 200 & 102 & 188 & 105 & 94 \\
\hline
\end{tabular}

coefficients $K_{\mathrm{HMF}}$ and $K_{\mathrm{LA}}$ are 69.3 and 1.62, respectively, which was obtained from the calibration graph shown in Figure 7.

3.4. A Dual-Wavelength Method to Determine the Content of $H M F$ and $L A$. In this paper, we developed a dual-wavelength spectrophotometric method to determine the contents of HMF and LA at the same time. As Figure 1 had shown previously, HMF and LA in the hot acid hydrolysis solution had the characteristic absorption at wavelengths of $284 \mathrm{~nm}$ and $266 \mathrm{~nm}$, respectively. Meanwhile, the absorbance at the scope of $250 \mathrm{~nm}$ and $350 \mathrm{~nm}$ was the contribution of HMF and LA. Based on Beer's law, the concentration of HMF and LA in the sample can be calculated according to the following equation:

$$
\begin{gathered}
A_{266}=\varepsilon_{\mathrm{LA}}^{266} C_{\mathrm{LA}}+\varepsilon_{\mathrm{LA}}^{284} C_{\mathrm{HMF}}, \\
A_{284}=\varepsilon_{\mathrm{HMF}}^{266} C_{\mathrm{LA}}+\varepsilon_{\mathrm{HMF}}^{284} C_{\mathrm{HMF}},
\end{gathered}
$$

where $A_{266}$ and $A_{284}$ are the absorbance after the sample was treated by charcoal at wavelengths of $266 \mathrm{~nm}$ and $284 \mathrm{~nm}$, respectively. $C_{\mathrm{LA}}$ and $C_{\mathrm{HMF}}$ are the diluted concentrations of LA and HMF in the sample after the sample was treated by charcoal, mmol/L. And $\varepsilon_{\mathrm{LA}}^{266}, \varepsilon_{\mathrm{HMF}}^{266}, \varepsilon_{\mathrm{LA}}^{284}$, and $\varepsilon_{\mathrm{HMF}}^{284}$ are 
TABLE 2: Contents of LA and HMF in the sample.

\begin{tabular}{lccccccc}
\hline Reaction time, $\min$ & 20 & 24 & 26 & 29 & 40 & 49 \\
\hline LA, g & 0.32 & 1.39 & 1.40 & 2.00 & 1.80 & 1.87 & 1.49 \\
HMF, g & 0.27 & 1.06 & 0.38 & 0.46 & 0.17 & 0.11 & 0.05 \\
\hline
\end{tabular}

the molar absorptivities of LA and HMF at wavelengths of $266 \mathrm{~nm}$ and $284 \mathrm{~nm}$, respectively, which can be achieved from Figure 2. Then, the $C_{\mathrm{LA}}$ and $C_{\mathrm{HMF}}$ can be written as

$$
\begin{gathered}
C_{\mathrm{LA}}=\frac{\varepsilon_{\mathrm{HMF}}^{284} A_{266}-\varepsilon_{\mathrm{LA}}^{284} A_{284}}{\varepsilon_{\mathrm{LA}}^{266} \varepsilon_{\mathrm{HMF}}^{284}-\varepsilon_{\mathrm{LA}}^{284} \varepsilon_{\mathrm{HMF}}^{266}}, \\
C_{\mathrm{HMF}}=\frac{A_{266}-\varepsilon_{\mathrm{LA}}^{266} C_{\mathrm{LA}}}{\varepsilon_{\mathrm{LA}}^{284}} .
\end{gathered}
$$

So, the content of LA and HMF in the hot acid hydrolysis solution of glucose can be calculated:

$$
\begin{gathered}
W_{\mathrm{LA}}=C_{\mathrm{LA}} * M_{\mathrm{LA}} * K_{\mathrm{LA}} * R, \\
W_{\mathrm{HMF}}=C_{\mathrm{HMF}} * M_{\mathrm{HMF}} * K_{\mathrm{HMF}} * R,
\end{gathered}
$$

where $W_{\mathrm{LA}}$, and $W_{\mathrm{HMF}}$ are the contents of LA and HMF in the hot acid hydrolysis solution, respectively, mg/L. $M_{\mathrm{LA}}$ and $M_{\mathrm{HMF}}$ are the molecular weights of LA and HMF, respectively. $K_{\mathrm{LA}}$, and $K_{\mathrm{HMF}}$ are the calibration coefficients of LA and HMF at wavelengths of $266 \mathrm{~nm}$ and $284 \mathrm{~nm}$, respectively. $R$ is the times of dilution.

\subsection{Measurement Precision and Method Validation. The} repeatability tests of the present method were conducted by adding some standard solutions of LA and HMF to a hot acid hydrolysis sample. The sample was measured by the present method, and the coefficients of recoveries of LA and HMF were calculated. The results are listed in Table 1 . It can be seen that the repeatability of the method had a relative standard deviation of less than $4.47 \%$ for HMF and $2.25 \%$ for LA, and the recovery ranged from $88 \%$ to $116 \%$ for HMF and from $94 \%$ to $105 \%$ for LA, which can meet the requirement of rapid measurement for HMF and LA.

3.6. Application. According to the present method, seven samples were measured to determine the contents of LA and HMF, and the results were listed in Table 2. It can be seen that the maximum content of HMF would be achieved at 24 min with the hydrolyze reaction going along, the content gradually declining, and the content of LA begining to enhance and meeting the maximum at $29 \mathrm{~min}$.

\section{Conclusions}

A very simple and rapid spectroscopic method to determine HMF and LA in hot acid hydrolysis solution of glucose had been developed. In this method, a sample was absorbed by charcoal, and direct UV absorption of the filtrate is then measured. The contents of HMF and LA can be calculated using a dual-wavelength (at $266 \mathrm{~nm}$ and $284 \mathrm{~nm}$ ) spectroscopic technique. The present method is simple, rapid, and accurate and has the potential for online process monitoring.

\section{Acknowledgments}

The authors are grateful to the financial support from Science and Technology Program from Science Technology Department of Zhejiang Provincial of China (2012C322080), Science and Technology Planning Program from Zhejiang Environmental Protection Bureau of China (2012B008), 521 Talent Cultivation Plan of Zhejiang Sci-Tech University, and the open fund of Key Lab. of Biomass Energy and Material of China (JSBEM201303).

\section{References}

[1] G. Taylor, "Biofuels and the biorefinery concept," Energy Policy, vol. 36, no. 12, pp. 4406-4409, 2008.

[2] J. J. Bozell, L. Moens, D. C. Elliott et al., "Production of levulinic acid and use as a platform chemical for derived products," Resources, Conservation and Recycling, vol. 28, no. 3-4, pp. 227239, 2000.

[3] L. C. Peng, L. Lin, J. H. Zhang, J. B. Shi, and S. J. Liu, "Solid acid catalyzed glucose conversion to ethyl levulinate," Applied Catalysis A, vol. 397, no. 1-2, pp. 259-265, 2011.

[4] J. Y. Cha and M. A. Hanna, "Levulinic acid production based on extrusion and pressurized batch reaction," Industrial Crops and Products, vol. 16, no. 2, pp. 109-118, 2002.

[5] C. Chang, P. Cen, and X. Ma, "Levulinic acid production from wheat straw," Bioresource Technology, vol. 98, no. 7, pp. 14481453, 2007.

[6] A. Espinosa-Mansilla, I. Durán-Merás, and F. Salinas López, "Kinetic determination of 2-furfuraldehyde based in a modified winkler's method," Journal of Agricultural and Food Chemistry, vol. 44, no. 10, pp. 2962-2965, 1996.

[7] T. C. O'Haver and G. L. Green, "Numerical error analysis of derivative spectrometry for the quantitative analysis of mixtures," Analytical Chemistry, vol. 48, no. 2, pp. 312-318, 1976.

[8] S. M. Rocha, M. A. Coimbra, and I. Delgadillo, "Occurrence of furfuraldehydes during the processing of Quercus suber L. cork. Simultaneous determination of furfural, 5hydroxymethylfurfural and 5-methylfurfural and their relation with cork polysaccharides," Carbohydrate Polymers, vol. 56, no. 3, pp. 287-293, 2004.

[9] J. E. Marcy and R. L. Rouseff, "High-performance liquid chromatographic determination of furfural in orange juice," Journal of Agricultural and Food Chemistry, vol. 32, no. 5, pp. 979-981, 1984.

[10] H. S. Lee, R. L. Rouseff, and S. Nagy, "HPLC determination of furfural and 5-hydroxymethylfurfural in citrus juices," Journal of Food Science, vol. 51, no. 4, pp. 1075-1076, 1986. 
[11] S. Albalá-Hurtado, M. T. Veciana-Nogués, M. Izquierdo-Pulido, and M. C. Vidal-Carou, "Determination of free and total furfural compounds in infant milk formulas by high-performance liquid chromatography," Journal of Agricultural and Food Chemistry, vol. 45, no. 6, pp. 2128-2133, 1997.

[12] A. Sano, T. Satoh, T. Oguma, A. Nakatoh, J.-I. Satoh, and T. Ohgawara, "Determination of levulinic acid in soy sauce by liquid chromatography with mass spectrometric detection," Food Chemistry, vol. 105, no. 3, pp. 1242-1247, 2007.

[13] J. J. Liu, "Determination of levulinic acid in soy sauce by headspace gas chromatography," China Condiment, no. 6, pp. 42-43, 2002.

[14] S. S. Li, C. L. Liu, and Y. R. Sun, "A gas chromatographic determination of the levulinic acid in soy sauce," Metrology and Measurement Technique, vol. 30, no. 2, pp. 43-48, 2003.

[15] M.-H. Yang and Y.-M. Choong, "A rapid gas chromatographic method for direct determination of short-chain (C2-C12) volatile organic acids in foods," Food Chemistry, vol. 75, no. 1, pp. 101-108, 2001.

[16] L. Cai, X. Y. Lu, L. He, W. L. Xia, and Q. L. Ren, "A gas chromatography method for direct measurement of Levulinic acid in biomass decomposition products," Journal of Instrumental Analysis, vol. 23, no. 6, pp. 104-105, 2004.

[17] H. C. Hu, Y. X. Tian, and X. S. Chai, "Rapid determination of formaldehyde in sanitary paper napkins for product quality control by headspace gas chromatography," Analytical Sciences, vol. 28, no. 7, pp. 689-692, 2012.

[18] J. Mark Green, "A practical guide to analytical method validation," Analytical Chemistry, vol. 68, no. 9, pp. 305A-309A, 1996. 

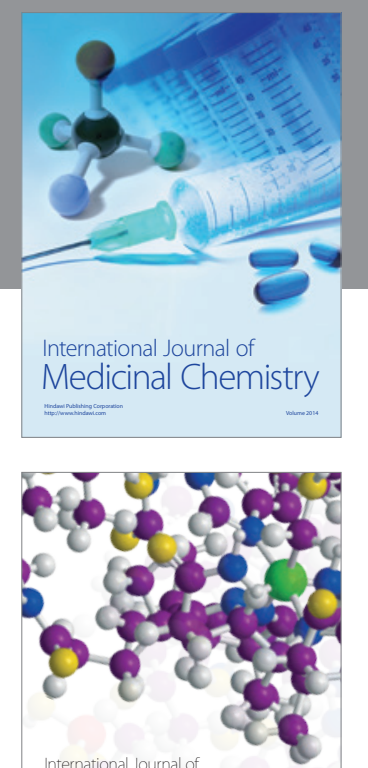

\section{Carbohydrate} Chemistry

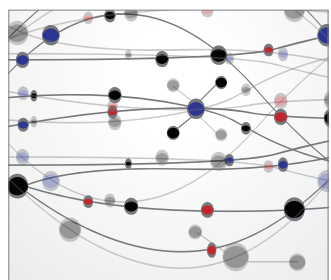

The Scientific World Journal
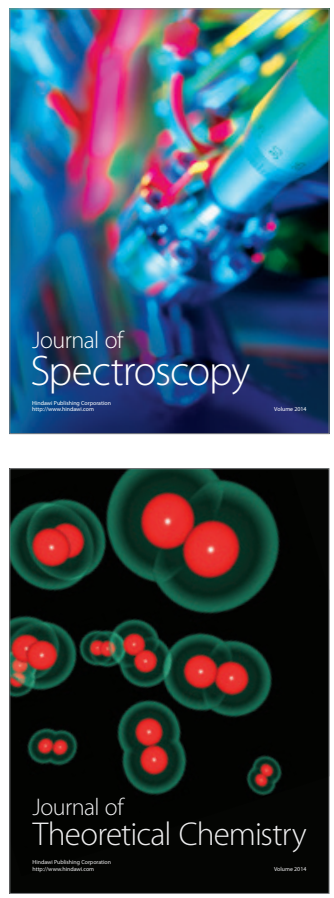
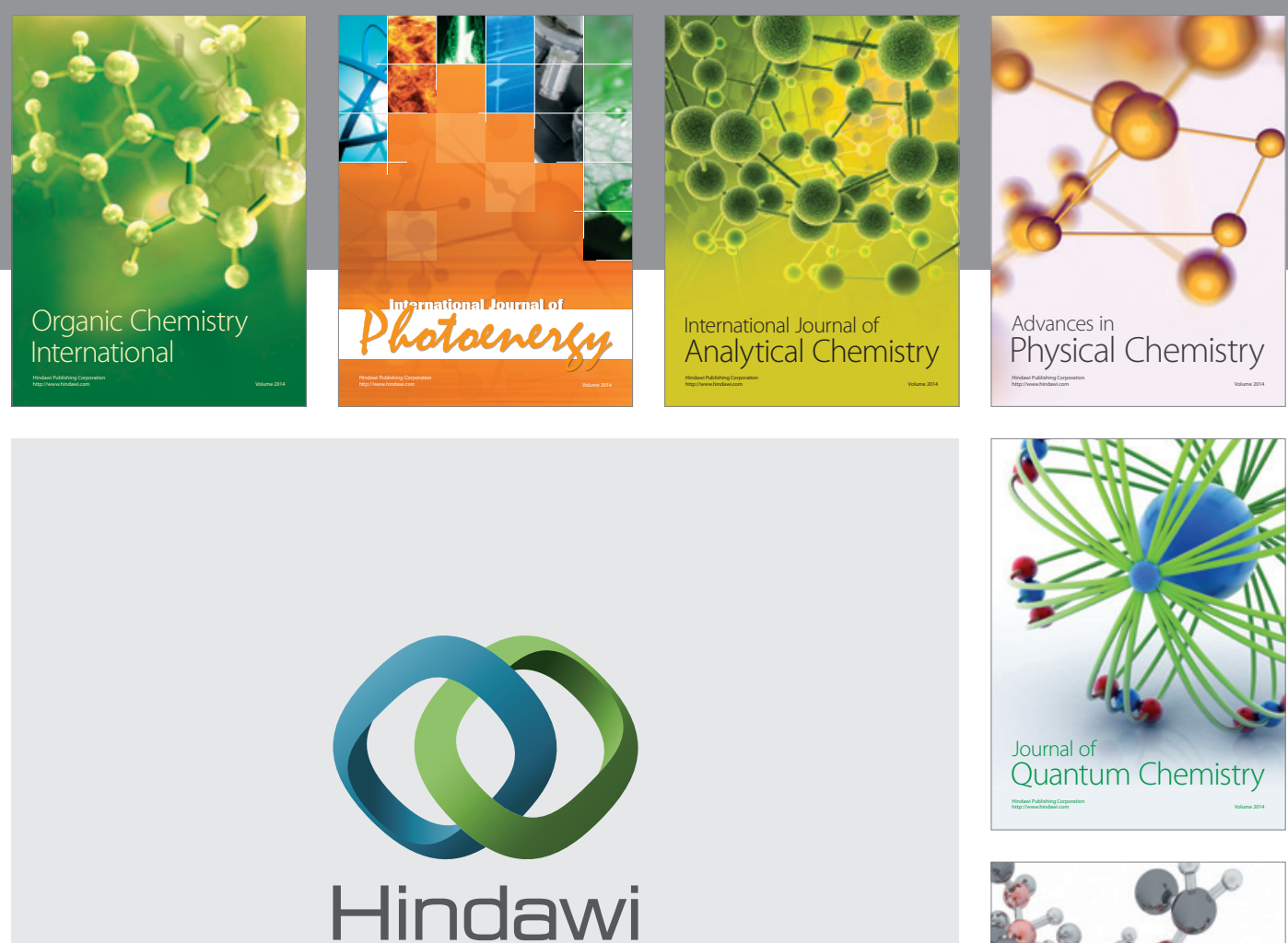

Submit your manuscripts at

http://www.hindawi.com

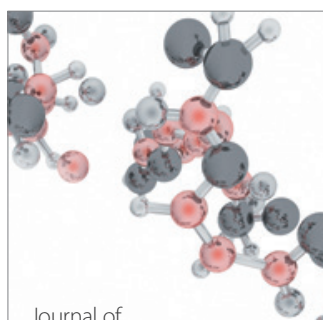

Analytical Methods

in Chemistry

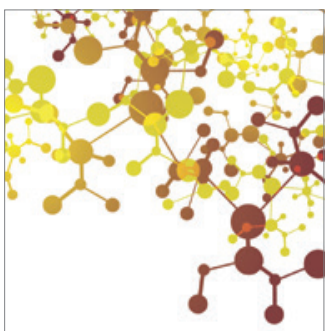

Journal of

Applied Chemistry

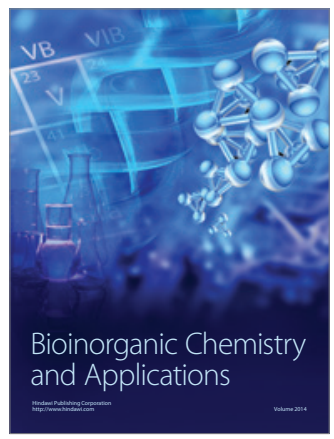

Inorganic Chemistry
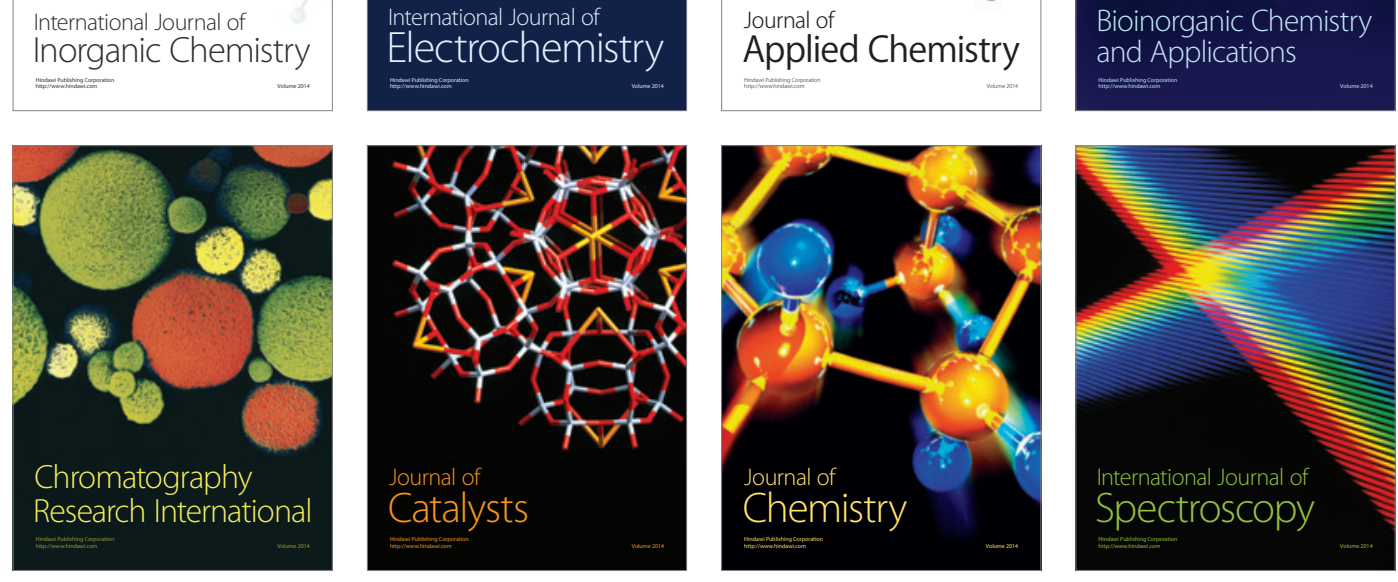